Revista Iberoamericana, Vol. LXXIX, Núm. 242, Enero-Marzo 2013, 43-55

\title{
DE LA ÉTICA EVANESCENTE DEL PERRO: COMUNIDAD, TEMPORALIDAD Y ALEGORÍA EN "EL TROVADOR COLOMBIANO”, DE RAFAEL ARÉVALO MARTÍNEZ
}

\author{
POR \\ Leonel Delgado Aburto \\ Universidad de Chile
}

La escritura, en 1914, del cuento "El hombre que parecía un caballo", de Rafael Arévalo Martínez, y su publicación en 1915 (Liano, “Nota” XXXI-XXXIII) señaló una fractura importante para la narrativa del modernismo hispanoamericano, entendida ésta tanto en sentido estricto (el desarrollo de un corpus de textos narrativos representativos de una tendencia y de una época) como alegórico (la gran narrativa del modernista hispanoamericano con su retórica, sus artificios, sus lugares comunes y su moral). Esta fractura es violenta y está impregnada de melancolía. El narrador del cuento, muy cercano a la máscara del mismo Arévalo Martínez, pasa del arrobamiento ante el modernista señor de Aretal y su retórica llena de piedras preciosas, a la decepción cuando advierte varias fisuras en esa retórica e imaginería modernista, y posteriormente a la admonición moral sobre tal figura que deviene monstruosa. Inicialmente el señor de Aretal aparece como "caballero de un antiquísimo culto" (Arévalo, Hombre 6) que arrastra al narrador a un intercambio vital trascendente, el cual se ve obscurecido por la revelación de su naturaleza equina. Tal percepción inicia, en realidad, en el momento del encuentro de ambos personajes:

Pero mi impresión de que aquel hombre se asemejaba por misterioso modo a un caballo, no fue obtenida entonces sino de una manera subconsciente, que acaso nunca surgiese a la vida plena del conocimiento, si mi anormal contacto con el héroe de esta historia no se hubiese prolongado. (5)

Este "conocimiento" sobre el modernista, antes oculto y subconsciente, permite ante todo la descripción de su amoralidad, y la promesa de su redención, como lo dice directamente el narrador al señor de Aretal: "Yo, que soy el primer hombre que ha amado a usted, he sembrado los gérmenes de su redención” (Arévalo, Hombre 13). Esta promesa es ambigua, y en los términos del mundo narrativo no se efectúa. Al contrario, traslada el poder trascendente del inicialmente poderoso modernista al narrador, y aunque éste parece querer cristianizar la amoralidad del señor de Aretal predicándole valores de amor 
y solidaridad, el cuento no termina con una eventual conversión humana del modernista, sino con un rompimiento en el que el caballo se subleva. El final de la narración dice:

De un bote rápido me lanzó lejos de sí. Sentí sus cascos en mi frente. Luego un veloz galope rítmico y marcial, aventando las arenas del Desierto. Volví los ojos hacia donde estaba la Esfinge en su eterno reposo del misterio, y yo no la vi. ¡La Esfinge era el señor de Aretal que me había revelado su secreto, que era el mismo del Centauro!

Era el señor de Aretal que se alejaba en su veloz galope, con rostro humano y cuerpo de bestia. (14)

El cuento alegoriza así varias fisuras internas de la retórica modernista: la naturaleza pagana de su culto, su moral y el sentido que adquiere la comunidad bajo sus preceptos. Una causa fundamental de la revelación de la naturaleza animal del señor de Aretal es que no reconoce el valor trascendente y la jerarquía de los contactos que establece, su tendencia a teñirse de la vulgaridad de sus otros eventuales acompañantes (Arévalo, Hombre 11). Arévalo parece radicalizar por voz de su narrador el establecimiento homosocial y exclusivista del Modernismo, y pide, incluso, “¡Respeto a la evolución!” (13), es decir, para los rangos sociales naturalizados. Adelantado lector de Nietzsche, ${ }^{1}$ Arévalo quiere llamar la atención hacia las jerarquías que potencial e inconscientemente abre la retórica modernista, y que el protagonista experimenta: “Jamás había sentido tan bien las posibilidades del hombre; jamás había entendido tanto al dios íntimo como en mis relaciones con el señor de Aretal” (10). Pero este advenimiento de posibilidades humanas negadas a la mayoría de mortales implica también un melancólico rompimiento interno: “[...] me era imposible desechar la melancolía del dios ido. ¡Traslúcidas, diamantinas alas perdidas! ¿Cómo encontraros los dos y volver a donde estuvimos?” (10). El rompimiento apunta a una paradoja: el estatus alienado del vínculo homosocial modernista es revelado y trascendido, pero en su lugar se instaura la melancolía de la pérdida, el enigma de los fragmentos de aquella retórica que parecía tan vital.

\section{Alegoría y SISTEMA CRÍTICO}

En este trabajo propongo leer esta ambivalencia como recurrencia, postulando que Arévalo debía "regresar" a ese punto de añoranza comunitaria en los diversos tonos que le facultaba su sistema narrativo. Entenderé en este caso la comunidad y lo comunitario a partir de la afirmación de Roberto Esposito en cuanto al "carácter originariamente melancólico, dividido, fracturado” de la comunidad (46), carácter que se hace evidente en los vínculos con procesos políticos generales de la modernidad y el capitalismo. En

\footnotetext{
1 Para el tipo de lectura de Nietzsche que hace Arévalo, véase Liano, “Algunas fuentes” 299-302, y Arias $371-74$.

$\begin{array}{llllll}\text { ISSN 0034-9631 (Impreso) } & \text { ISSN 2154-4794 (Electrónico) }\end{array}$
} 
términos ontológicos, Esposito concibela comunidad no como algo opuesto a la melancolía y la separación entre los sujetos, sino, por el contrario, como la esencia misma de esa separación (47). De esa forma, el pensamiento de la comunidad estaría unido al proceso político reciente de defunción del comunismo como gran utopía, acontecimiento que faculta volver a plantearse la genealogía de la comunidad, describiéndola, tal lo hace Jean-Luc Nancy, como "el invento tardío que intentó responder a la dura realidad de la experiencia moderna” (32). Fundamentalmente, en "El trovador colombiano", que es consecutivo a "El hombre que parecía un caballo", 2 pueden advertirse las estrategias de recurrencia en la restitución de la comunidad homosocial y el quebrantamiento melancólico de tal comunidad. Es, además, en "El trovador colombiano" en donde puede leerse la calidad alegórica de tal ansiedad comunitaria, es decir, en lo que puede tener ésta de social, pues hay marcas en el texto que aluden tanto a un estatus neocolonial de las naciones centroamericanas de principios del siglo xx como a la interpelación a una cultura popular de carácter nómada. En contraste con la ampulosidad y la melancolía de "El hombre que parecía un caballo" en "El trovador colombiano" Arévalo hace funcionar un sistema irónico mucho más intervenido por discursos alternos y ofrece así un texto mucho más dialógico.

El quiebre significativo y simbólico de estas narraciones de Arévalo opera a partir de una ubicación doble que permite que su efecto crítico funcione hacia adentro de la lógica prosódica-narrativa de las narraciones, como cuentos aislados, pero también hacia el exterior sobre el modernismo como movimiento literario y cultural establecido. Se trata de una articulación alegórica que implica, además de una crisis individual y contextual -la del propio Arévalo como fabulación de sujeto decadente hispanoamericano, rol que él se solazaba en aceptar y representar ${ }^{3}$-, la crisis de agotamiento del modernismo, la que ha sido descrita por la historia literaria como posmodernismo. Los textos de Arévalo poseen, pues, una ubicación por decirlo así "exterior" en el sentido que operando con los grandes ideales del modernismo, con su retórica y sus lugares comunes, abandonan parcialmente esa lógica para ironizarla. Esta operación no puede ser llevada a cabo sin un movimiento temporal típicamente alegórico por cuanto implica la repetición y, según explica Paul de Man, el signo que se intenta repetir en el lenguaje alegórico es "pura anterioridad" (207). En este sentido, Arévalo trabaja con lo que Hayden White llamaría un referente narrativo secundario (42), en que se percibe la narrativa heroica del modernista, trama que es repetida pero, a la vez, ironizada en la figura alegórica. En esta convivencia de dos órdenes conviven también dos temporalidades. En un primer momento se da la revelación de "las piedras preciosas" y la comunión de las subjetividades elegidas, el despliegue armónico del núcleo de artistas modernos. En

2 "El trovador colombiano", publicado en la primera edición de "El hombre que parecía un caballo" (1915), fue escrito “entre noviembre de 1914 y abril de 1915” (Liano, “Nota” XXXIII).

3 Para el aspecto biográfico unido al representacional y la figura del decadente, véase el ensayo de Martin.

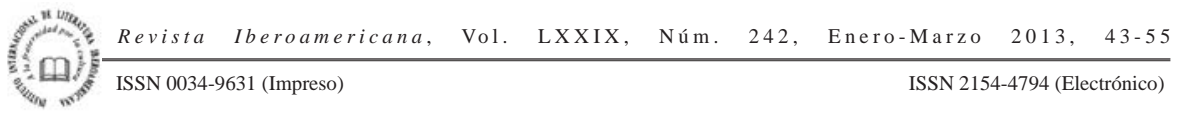


un segundo momento, esta retórica es puesta en cuestión y la comunidad se fragmenta y se sume en la melancolía, aun cuando su ideología y estrategias de reproducción sean repetidas. La figura monstruosa del modernismo una vez revelada no puede ser repetida como tal sin dejar ingresar un pensamiento crítico. El movimiento alegórico permite pensar, pues, las consecuencias de una crítica radical hecha desde dentro de un movimiento artístico, la que a la vez no logra un rompimiento con la lógica "política" de tal movimiento: en el caso de Arévalo, expresada por una jerarquización del mundo en base a valores como la raza.

Esta maquinación crítica desde dentro del modernismo, tan íntimamente ligada a la temporalidad, tiene otra consecuencia importante. El rompimiento de la comunidad “originaria” modernista, y el proceso de (re)jerarquización que le sigue, descentran los órdenes del discurso al llamar la atención sobre su estatus precario y convencional. Este aspecto ha recibido atención especialmente en la coyuntura posvanguardista que inicia en la década de 1950, cuando la antipoesía de Nicanor Parra y las llamadas poesías conversacionales relativizan las retóricas de la primera vanguardia. Es entonces cuando el primer posmodernismo (el latinoamericano) recibe nueva atención y con él, aunque sea de forma marginal, la literatura de Arévalo Martínez. Ese elemento crítico que embebe la narrativa de Arévalo retorna, pues, en discusiones más amplias sobre la naturaleza del texto moderno y modernista, $y$, del sentido que tiene el texto oposicional a la retórica modernista inicial.

Según Roberto Fernández Retamar las antipoesías son movimientos de reacción a las poéticas realmente productivas, en ese sentido son dependientes, "caminos cerrados”, sin posibilidades de hacer evolucionar la poesía. Retamar remonta una potencial contradicción entre Ernesto Cardenal (el poeta que logra un movimiento de propagación de la poesía) y Nicanor Parra (el antipoeta esterilizado por el mero rechazo de una poética anterior, en este caso la de Neruda) a una contradicción cíclica de la historia literaria hispanoamericana. Su lectura es parcialmente borgeana en el sentido que la contraposición posvanguardista entre poesía conversacional y antipoesía, que se hace visible a partir de los años cincuenta, es la que permite una invención de coyunturas precursoras. Así, Retamar observa la existencia de antipoesías correspondientes al Romanticismo y al Modernismo. Dentro del posmodernismo (por supuesto, en una cronología que no corresponde al anglo postmodernism), ${ }^{4}$ Fernández Retamar menciona de paso a Arévalo Martínez (89), quien, siguiendo la lógica de las contraposiciones, formaría parte de la antítesis crepuscular del Modernismo. El asunto se vuelve más

\footnotetext{
4 Como discuto a continuación, hay posiciones encontradas con respecto a la existencia de un posmodernismo cuya cronología y localización cultural, a inicios del siglo xx en América Latina, lo distancia del actual posmodernismo global. A lo largo de este texto usaré "posmodernismo" en ese sentido cronológico y latinoamericano, sin vínculos con lo que se entiende por posmodernismo global en la actualidad.

$\begin{array}{llllll}\text { ISSN 2154-4794 (Electrónico) } & \text { Iberoamericana, Vol. LXXIX, Núm. 242, }\end{array}$
} 
sugestivo si se piensa que el mismo Arévalo convirtió la máscara de decadente en uno de los modos preferidos de su enunciación como autor (Arévalo, Vida 52). De manera que hay algo que desde el juego representacional desarrollado por el guatemalteco parece responder al planteamiento de Fernández Retamar. Pero también podría percibirse un movimiento en sentido contrario, pues el aspecto decadente desarrollado por Arévalo puede ser aplicado a la interpretación de las antipoesías. Según Fernández Retamar, "se trata de poesías que se encuentran ante la dificultad de seguir a ricos momentos poéticos" y hacen "un esfuerzo desesperado por escapar a las monumentales cristalizaciones previas” (88). En el caso de Arévalo Martínez esta gran cristalización previa sería el modernismo hispanoamericano, y más propiamente la poética de Rubén Darío. En este esquema la literatura de Arévalo estaría signada por una maquinación anti (o pos) que activada desde dentro del modernismo procura de alguna manera escapar de sus designios estéticos y políticos. Por su parte, Octavio Paz descree de la existencia de un movimiento posmodernista hispanoamericano, reconociendo, sin embargo, la existencia "de una tendencia dentro del modernismo" (énfasis de Paz) constituida en "una crítica del modernismo dentro del modernismo"; "su conciencia crítica, la conciencia de su acabamiento” (102). Desde ambos puntos de vista, el rol del Posmodernismo (y, con él, el de Arévalo) sería o de oposición estéril (siguiendo la lógica de Fernández Retamar), o de señalización crítica de un final (siguiendo a Paz).

Por supuesto, varios problemas metodológicos surgen a partir de este tipo de contraposiciones; unos generales, relativos a cómo se determina la fertilidad o esterilidad de una poética, y qué rol tendrían frente a la poesía como género específico, la narrativa (que en el caso de Arévalo Martínez es fundamental) y otros géneros. ¿Cabe aplicar a la narrativa modernista y posmodernista la lógica del "anti” improductivo? Como ha señalado Paz, en la tradición moderna occidental la heterogeneidad textual es un elemento decisivo, de manera que en ella se conjugan no solamente poesía y poética, la práctica del arte y su teorización, sino que también surge un "diálogo entre prosa y poesía” que logra "idealizar la prosa, disolver la lógica del discurso en la lógica de la imagen” (66). Precisamente la prosa modernista hispanoamericana (y dentro de ella, la de Arévalo Martínez) recurre a esta estrategia de interconexión plástica de diversos niveles del discurso que, por otra parte, termina por cuestionar el nivel meramente anecdótico de la narrativa de manera que la "disolución” en la imagen que Paz percibe puede ser, asimismo, cuestionada. En efecto, al hibridarse el discurso narrativo no sucede necesariamente una suspensión del potencial crítico; de hecho, en Arévalo, la discordancia entre el modernista “animal” y el "humano" no permite pensar una hibridez sin conflicto. Paz tiende a ofrecer una lectura monológica o apolínea de la prosodia modernista, lo que deja traslucir un deseo de soldar la heterogeneidad probable del texto en torno a la imagen. En contraste, mi lectura del texto de Arévalo apunta a determinar el permanente estatus fragmentado de la imagen alegórica que es notable en sus narraciones.

\footnotetext{
Revista Iberoamericana, Vol. LXXIX, Núm. 242, Enero-Marzo 2013, $43-55$
ISSN 2154-4794 (Electrónico)
} 
"LOS GRANDES SERES QUE SE AVECINAN"

"El trovador colombiano” podría ser leído como la descripción lírica y hasta cierto punto itinerante de una serie de reuniones del grupo de artistas del círculo del señor de Aretal, narradas en primera persona. Lo que encadena la serie de encuentros con la visión subjetiva del narrador, que se confunde (auto)biográficamente con Arévalo, es la revelación de que el trovador León Franco tiene "pobre ánima de perro callejero” (15) y la relación que se establece entre ambos. Si en "El hombre que parecía un caballo” la narración está dominada por el encuentro apasionado con Aretal, dando un efecto mucho más individualizado al encuentro (las dos subjetividades que se entrelazan, colisionan y se dispersan), en "El trovador colombiano" se narra lo que ocurre tanto en el centro como en los márgenes del grupo modernista, sus motivaciones y las asimetrías de su organización, de manera que la narración resulta mucho más heterogénea y sinuosa, aunque igualmente melancólica. El señor de Aretal mantiene su rol de líder del grupo en este cuento, pero pierde su calidad de símbolo central. "El trovador colombiano" investiga, menos que el símbolo trascendente del ser mitológico híbrido, mitad animal mitad humano, las posibilidades de (re)producción de estos seres a partir de la disciplina comunitaria, incluidos "los grandes seres que se avecinan" (17), con lo que Arévalo alude a un horizonte nietzscheano que parece tener muy presente. A pesar de que en esta producción de seres la procreación por vía sexual está ausente (de hecho se trata de grupos con exclusividad masculina), uno de sus fundamentos es la corporalidad imaginada. La castración simbólica, la división en razas, las tecnologías del cuerpo relacionadas con la modernidad, permiten la reafirmación de las jerarquías. Podría sugerirse, incluso, que las relaciones de poder del grupo modernista poseen un matiz biopolítico evidente.

La reproducción biológica es introducida como tema desde el primer párrafo del cuento, en donde se revela que Franco es un perro "mutilado y triste como las bestias que el buen Jesús llamó a su pesebre” (15), es decir, emasculado. Irónicamente, más adelante, el señor de Aretal, que no deja de maquinar los temas de la modernidad, aparece retirado del grupo y leyendo "un estudio sobre la fertilidad de la Judea" (24). Este paradójico interés en la fecundidad es parte de una continua sublimación de la reproducción. Las reuniones bohemias fundamentalmente homosociales que se dan en torno a Aretal provocan en los participantes el efecto de un encuentro sexual. Según el narrador, luego de una de esas reuniones en que Aretal "dejaba fluir el chorro comunicativo [...] nos retirábamos a nuestros lechos, rendidos y gozosos como un amante después de una noche de amor" (15). En el momento climático del cuento, el narrador revelará su "odio al contacto de la tierra” y su "amor al agua”. El agua cumple aquí la función de elemento sublimador de la reproducción, como se puede percibir en la alusión a cómo se reproduce la valinceria, una planta acuática que "tiene sus raíces en el limo”, y cuyo "largo tallo... es la más sagrada aspiración a Dios que conozco” (28). La reproducción aparece, pues,

Revista Iberoamericana, Vol. LXXIX, Núm. 242,
ISSN 0034-9631 (Impreso) 
intervenida y jerarquizada por ciclos y elementos naturales, aunque ausente como tal porque se refiere a la (re)producción mental y corporal de la modernidad dentro de una especie de grupo de vanguardia. La observación que hace Edward Said en cuanto a cómo los grupos de artistas modernos rompen con la filiación para formar lazos afiliativos en un orden social compensatorio (34), parece pertinente aquí. La estructura "formal" de la filiación dentro de la prosodia (pos)modernista parece responder a una alegoría de la reproducción de seres que se localizan fronterizos entre una estructuración provinciana de la modernidad y una modernidad supranacional, en este último caso un discurso que se abstrae de las circunstancias para intentar trascender sus propios límites.

Podría decirse por eso que no se puede releer la narrativa de Arévalo sin replantearse cómo las comunidades de la élite intelectual modernista que tenían un fuerte componente cosmopolita e itinerante se plantearon críticamente el problema del anclaje en territorios como las capitales centroamericanas que carecían de la sofisticación moderna que daba sentido al modernismo. Este problema es enunciado como un lamento del "ultra urbano señor de Aretal” (24):

-iVaya! Ahora comprendo que en esta mínima ciudad un hombre culto no pueda ni leer a Platón, ausente de las librerías que llena López Bago; ni leer a Biltis, ausente de librerías que llena Carlota Braeme; ni encontrar trajes para hombres en sastrerías que visten oranguntanes; ni pedir a un facultativo que le desocupe el vientre, turbado de vino, media hora antes de concurrir al banquete de un amigo. Ahora comprendo que en ella no existan ni pedicuros, ni baños confortables, ni siquiera un buen chocolate... Pero ¡es comprensible! Una metrópoli que tiene un bosque por casquete y otro bosque por pantuflos y un tercer bosque a cien metros de su catedral... (25)

El énfasis está puesto en la carencia de elementos culturales (libros y librerías) y de disciplina corporal (vestido, digestión, cuido corporal) en la típica capital centroamericana de la época y su estructuración urbana. Este estado cultural y espiritual es el medio en que el núcleo de artistas modernos debe operar. La ansiedad del planteamiento sobre la comunidad, tal como aparece en "El trovador colombiano", está vinculada a ese proceso cultural de establecimiento crítico de un posmodernismo que intenta disciplinar su propia excentricidad cosmopolita. Contextualmente, podría alegarse que tanto cuando Retamar teoriza una poesía de propagación frente a una poesía de conservación (antipoesía), o cuando Octavio Paz (45-46) quiere identificar el arte moderno con un ideal comunitario primigenio, estamos ante proposiciones que tienen por referente comunidades ideales localizadas bien sea en el futuro o bien sea en ciclos marcados por las coyunturas revolucionarias de la historia moderna. Lo que la narrativa de Arévalo integra a esta articulación crítica de la modernidad es la posibilidad zoomórfica, es decir, el diseño de seres ambiguos vinculados con estados ontológicos híbridos arraigados a una situación cultural específica: la de Centroamérica a principios del siglo xx.

\footnotetext{
ISSN 0034-9631 (Impreso)
} 
TAXONOMÍA Y NARRATIVIDAD

La retórica del cuento responde a estos cometidos de reproducción corporal y jerárquica, organizada en torno a la revelación del carácter canino de Franco, y sobre todo a que los repetidos encuentros de los artistas provocan una revelación zoomórfica en el propio narrador durante el clímax de la narración (28). En este sentido es evidente en el cuento un carácter cíclico que hace avanzar lentamente la anécdota, rodeándola de un lenguaje trascendente, en donde no están ausentes los balbuceos del narrador sobre su propia posibilidad de contar, y en donde la alegoría (como conocimiento por imágenes que trasladan un saber no común) predomina. Desde el punto de vista de la anécdota, estos ciclos podrían describirse de la siguiente forma:

1. La cercanía del narrador y el perro; en donde se podría distinguir una estructuración doble: la posesión del perro que el narrador desea, y la posibilidad de establecer con él una relación amo-esclavo que conduzca a un equilibrio personal de la naturaleza aristocrática del narrador.

2. La naturaleza itinerante del trovador, que hará que se aleje del país pronto; su necesidad del poder político, de los ministerios, para financiar su viaje (y si se lee contextualmente, de la dictadura de Estrada Cabrera).

Su calidad itinerante depende de un arreglo con el poder, pero cuando consigue el dinero para viajar, el trovador se parrandea el dinero del pasaje junto a todo el círculo de Aretal y eso lleva a un momento histriónico en que el narrador (el álter ego de Arévalo) revela su alma de ave, de grulla, y su ubicación acuática, su "sabiduría de agua y sombra”. Así, revelación y rompimiento de la comunidad quedan interrelacionados. Al final, el trovador colombiano logra irse del país, hacia la irónicamente llamada "odorante Honduras".

El cuento está concebido, pues, en torno a un rompimiento interno: el narrador/ Arévalo no puede poseer al perro, al menos no en el sentido de crear un nuevo espacio de comunidad basada en un sistema de castas y esclavitud, como el narrador parece desear. En un circunloquio en que se refiere a su capacidad para amar y someter a "hombres gordos”, ante quienes él representa al ser humanizado, humanizándoles por eso su naturaleza perruna, dice el narrador que "Se puede llegar a comprender que las castas y la esclavitud sean de origen divino y de esta comprensión a llegar al origen divino de los reyes hay sólo un paso" (19). La naturaleza itinerante de Franco impide la estructuración de esa especie de micropolítica esclavista en su relación con el narrador. A la vez este impedimento conlleva una revelación ulterior y trascendente: definir el estatus existencial y cultural del modernista de provincias, ese ser que vive como las plantas acuáticas con las raíces en el limo y una aspiración hacia el aire del exterior. Parte de lo que une al núcleo de intelectuales modernistas es una poética de la armonía entre arte y naturaleza. El narrador se refiere, por ejemplo, a que el "noble espíritu" del señor

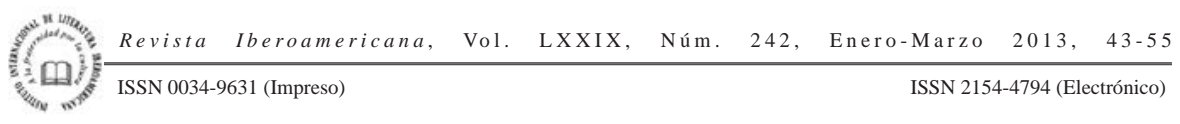


Aretal “cantaba, sin disonar, en armonía con las voces de todos los seres creados” (20). La narración de Arévalo introduce a la vez una disonancia en este dominio armónico y un intento de readecuación. El acto de narrar mismo es un indicio de esta intervención disonante e irónica. El problema es retórico: si el grupo modernista se constituye como enclave intelectual que busca la revelación de la verdad, ¿cómo se va comunicar tal revelación? Y quizá un poco más al fondo, si el enclave intelectual implica una ruptura individual interna (una afirmación egoísta o una disonancia existencial), ¿cómo se va a narrar esa verdad y su precariedad provinciana? Se presenta así un conflicto entre posesión y pérdida visible cuando el narrador lamenta su estado incompleto:

León Franco fue una cosa mía desde que lo vi. Pero ya estoy cansado: acabemos aprisa este cuento, que si no queda en el limbo que lloró Bécquer. Todavía no he encontrado un ser que me preste la corporeidad que falta a mi espíritu sin materia agente. Por eso mi estilo es doloroso e inquieto y tiene una unidad impalpable, percibida por muy pocas almas. Por ello me refugié en el verso. Pero ¿cómo contar en verso estas visiones? (19)

Éste es un problema retórico fundamental: si el modernismo otorga a los intelectuales la capacidad de percibir visiones, ¿cómo se trasladarán éstas al dominio de los discursos? La visión sólo se comunica de manera espasmódica y oscura, y en esta alegoría de enunciación el narrador es un moribundo:

Si vierais lo que me cuesta decir lo que tengo que decir, es un mensaje divino; pero tengo tan mala memoria que se me olvidaron las palabras de mi mandatario. Soy como esos moribundos que no aciertan a comunicar sus visiones celestes, ni al doctor, que ríe y habla de delirios, ni a los deudos que rodean su lecho, que no entienden, pero que se sienten conturbados. Estoy casi del otro lado de la vida: hace catorce años que empecé a morir... (22)

Arévalo marca aquí el vínculo entre discurso y producción de subjetividad. La forja del decadente centroamericano (uno de los grandes temas de su literatura) implica una disciplina hermenéutica: aclarar el propio discurso en un momento crítico y en una situación límite de carácter retórico. En otras palabras, hacer posible que las “visiones” y seres que el grupo modernista produce se hagan inteligibles en el contexto histórico que les toca. La petición hermenéutica podría aludir concretamente a que la revelación de que Franco es un perro (un perro interno, podría decirse) debe producir un efecto interpretativo, aunque este efecto no pueda ser enunciado de manera positiva. Tenemos así algo cercano a la reticencia interpretativa de la alegoría que, de acuerdo con Benjamin, (re)presenta un sentido agónico y petrificado de la historia. Al enfatizar este carácter decadente, la alegoría demarca también la sujeción del hombre a la naturaleza y a la muerte. La índole productiva de la alegoría parece residir en presentar las estaciones de

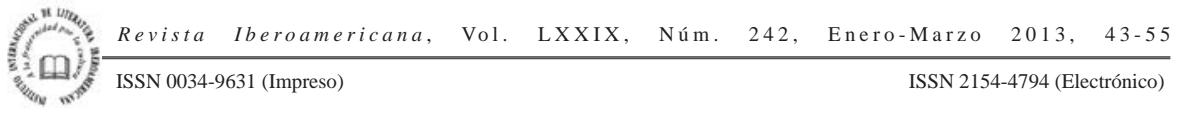


la historia como pasión secular (Benjamin 166). Además de esa profunda conciencia de decadencia que exhibe Arévalo ("Estoy casi al otro lado de la vida..."), en su cuento el artificio modernista es llevado a un estatus biológico localizable en la genealogía que va de Darwin a Nietzsche (dos de sus influencias reconocidas). ${ }^{5}$ Según Esposito, esta genealogía rompe con la tradición humanista al orientarse por la idea de que: "la naturaleza humana no es un todo que progrese hacia su mejora, sino el resultado, siempre modificable, de un conflicto inagotable entre tipos biológicos diversos que compiten por afirmarse" (163).

$\mathrm{Al}$ respecto, la taxonomía de los canes en el cuento de Arévalo, que ocupa varios párrafos del inicio del cuento (16-17), es vital. ¿Qué tipo de perro es Franco? El centro del argumento taxonómico, lleno de vaivenes y repeticiones, es que Franco representa al vilipendiado perro familiar, cuya característica principal es su posición en una cadena de humanización: un perro sometido a un proceso antropomórfico, en esencia un devenir, así como el artista que se acerca al ángel es también un devenir (17). La identificación zoomórfica en Arévalo es paradójica: alguien es animal porque avanza hacia la humanización. Es decir que Arévalo no cuenta, como Augusto Monterroso, fábulas humanas bajo figuras de animales, sino más bien ubica al ser humano en ese estadio de transición típicamente nietzscheano. Las jerarquías se instalan en todos los ciclos vitales y naturales, desplegando lo que José Santos Chocano llamó “darwinismo espiritual” (Liano, “Algunas fuentes” 293). Las siguientes frases del cuento pueden resumir bien este aspecto, y revelan cómo la concepción biológica afecta a toda la naturaleza: “¿qué es un árbol sino una aspiración de la tierra a los cielos? ¿qué es un animal sino un árbol desatado? ¿qué es un hombre sino un animal con manos tendidas hacia lo azul?” (22).

Tenemos pues dos claves decisivas en la interpretación de la narrativa de Arévalo: en primer lugar, el estatus espasmódico y oscuro de las visiones que trata de comunicar, que puede referir a un sistema alegórico; y, en segundo lugar, una concepción de los seres en devenir que se expresa por una ansiedad taxonómica. Estas posiciones son elaboradas en forma narrativa desde dentro del grupo modernista, y, en cierta medida, operando como crítica irónica de la armonía supuesta entre sociedad y cultura que el modernismo proponía. Por otra parte, queda todavía por pensarse de una manera mucho más radical el significado de este énfasis en las supuestas jerarquías naturales y la naturalización de una supuesta "evolución” y taxonomía de seres, enunciados desde territorios como los centroamericanos de principios de siglo, que estaban ferozmente dominados por el racismo. La popular idea de Benedict Anderson de la nación como “comunidad imaginada” tendría en la prosodia posmodernista de Arévalo una versión

5 Según Liano (“Algunas fuentes” 293-99), la influencia de Darwin en Arévalo no es directa sino que está tamizada por su lectura de La doctrina secreta, de Madame Blavatsky.

$\begin{array}{llllll}\text { ISSN 2154-4794 (Electrónico) } & \text { Iberoamericana, Vol. LXXIX, Núm. 242, }\end{array}$ 
bizarra en que, en vez de revelarse la comunidad en torno a valores libertarios, parece haberse internalizado una especie de biopolítica global tamizada sin duda por el positivismo predominante en la época. ${ }^{6}$

Para volver parcialmente al problema del anti o pos en los cuentos de Arévalo, habría que hacer algunos planteamientos desde la taxonomía elaborada por el cuento. ¿Podría contraponerse la familiaridad del perro como ente producido por el grupo modernista con la artificialidad del modernismo, en el sentido de la reacción prosaísta y anti-poética al preciosismo dariano? Se diría que Arévalo tiende, en este aspecto, a proponer una alegoría social: al describir una clasificación de los perros va identificando funciones y niveles sociales diversos, desde la función de los poetas como "perros de adorno", hasta la identificación de la caficultura en los perros de presa que asocia con "tres alemanes montados en tres pesados y enormes caballos yanquis” descritos junto a ellos (17). La taxonomía está asociada también con la revelación. Como los cubistas o impresionistas, o como El Greco, el narrador dice "[...] ver las cosas alargadas, como si una eterna luna proyectara eternamente sus sombras en mi espíritu. Es que el superhombre se acerca y lo precede el super arte" (17). El perro familiar podría leerse, pues, como un punto de equilibrio entre la función alienada tanto del perro del adorno social (el poeta) como del perro de la intervención neocolonial: un avatar hasta cierto punto emancipado que escapa al anclaje decadente del narrador y a la lógica estratificada del grupo modernista. El deseo de posesión de este canis familiaris se ve impedida por la mirada moderna y seudomística del narrador y por la ética propia del perro. El perro familiar, podría decirse, es el animal no fijado a un contexto, y Arévalo y los modernistas, sobre todo cuando están atados al contexto nacional, no pueden perseguir la ética itinerante del trovador. Se marca así el límite de su propia alienación o su propia animalidad en el mismo sentido en que en "El hombre que parecía un caballo" el señor de Aretal no puede abandonar su esencia animal y mitológica.

Se hace evidente, además, otro conflicto relacionado con la taxonomía: en el momento cumbre de la narración el narrador revela que es una grulla, como tal un ser feminizado e histérico, además, decisivamente anclado al contexto. Arévalo no duda en introducir la autoironía y se describe como ave, marcando su vínculo con el histerismo y la feminización. Pero lo fundamental aquí es que su contacto con el agua, elemento sublimador, le permite entender la lógica cultural del arraigo posmodernista tal como lo observa en una planta acuática:

Yo quisiera contar, sobre todo, la historia de la valinceria que he escuchado. La valinceria tiene sus raíces en el limo, bajo las aguas. En sus raíces hay una innata aspiración hacia medios más tenues. La ahoga el medio denso que la rodea: ella ama el agua, pero presiente el aire. Y se prolonga dolorosamente en un largo tallo, que es la más

6 Paradójicamente, Paz lee el modernismo como “respuesta al positivismo” (94).

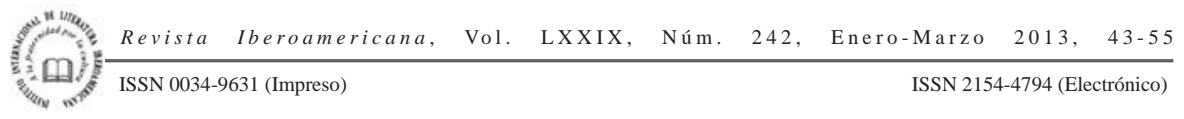


sagrada aspiración hacia Dios que conozco. Cuando llega la época de su fecundación, redimida por el amor, al fin hacer emerger sobre el agua una límpida flor de anhelo. Llega, flotante, salido de ella misma, el espíritu viril que ha de hacerla concebir y la llena. Y entonces, el tallo, resignadamente, se vuelve al limo de su origen; gesta un vástago y muere. Del loto indio ya se hizo el símbolo de la aspiración hacia Dios. (28)

En esta cita coinciden el hermafroditismo, la partenogénesis, y vida anfibia como aspiración y sublimación. Todo en esta circunstancia acuática del narrador, grulla y planta, apunta a un doloroso reconocer del contexto. La impotencia zoomórfica de la grulla/ Arévalo es doble: no posee el carácter itinerante del perro/Franco ni el cosmopolitismo del primer modernista representado por el caballo/Aretal. En la imagen se unen, pues, el deseo de producción subjetiva, el reconocimiento de la jerarquía y la melancolía de la pérdida comunitaria implícita en esa misma jerarquía. Despegado, y quizá desapegado, del orbe modernista, el narrador relata en términos alegóricos un ciclo de implantación cultural idealizado, carente y contradictorio, como suponemos fue el caso del llamado posmodernismo.

\section{Conclusiones}

Algunas breves y provisionales conclusiones resultan pertinentes en este punto:

1. Al contrario de lo que piensa Fernández Retamar, las anti-poesías (por ejemplo, el posmodernismo) son también movimientos fundacionales, fuertemente arraigados a sus contextos y con una complejidad hermenéutica muy marcada.

2. La expresividad alegórica de estos movimientos, tiende a ser oscura, y no se disuelve en la imagen (como parecía creer Octavio Paz). A la vez, acumulan mucho material de crítica social y dificultan una lectura denotativa. La mirada "alargada" sobre la realidad parece un arma de penetración social que, a la vez, no encuentra un asidero político.

3. La taxonomía zoológica es necesariamente fragmentaria. En el caso de Arévalo, esta fragmentariedad está teñida de nostalgia. Se deplora la posibilidad de un encuentro válido con un ser doméstico que reconozca el lugar aristocrático y dirigente de la clase intelectual. Se aplica, además, un biologismo y una racialización que hace colindar al modernismo con el positivismo y con un pensamiento biopolítico.

4. La estética posmodernista tampoco puede atrapar al trovador popular, o a la cultura popular, sino solamente establecer circuitos de acercamiento impregnados de melancolía; así, en este cuento se deplora la imposibilidad de posesión del perro/trovador colombiano. El devenir de los "grandes seres que se avecinan" implica un permanente desgarramiento y una desidentificación.

5. La conexión heterodoxa de la narrativa de Arévalo con el pensamiento de Nietzsche y Darwin es un indicio de la nueva colocación a que arrastra al modernismo

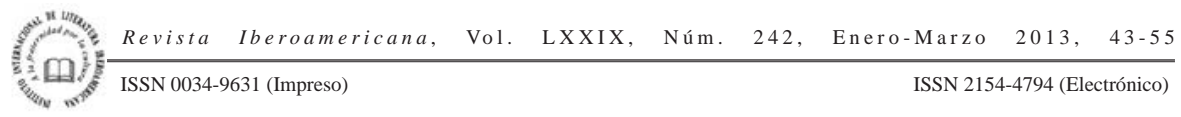


la implantación nacional. La nación/comunidad parece ser pensada como articulación biológica, urgida de una taxonomía que diera sentido a la modernidad bajo condiciones racializadas que caracterizaban a Centroamérica.

\section{BiBLIOGRAFÍA}

Anderson, Benedict. Comunidades imaginadas: reflexiones sobre el origen y la difusión del nacionalismo. México: Fondo de Cultura Económica, 1993.

Arévalo Martínez, Rafael. El hombre que parecía un caballo y otros cuentos. Madrid: Archivos, 1997.

Una vida. Guatemala: Ministerio de Cultura y Deportes, 1997.

Arias, Arturo. "Caballo viejo de la sabana versus perro hambriento. La estética simbólica como eje narrativo". El hombre que parecía un caballo y otros cuentos. Rafael Arévalo, ed. Madrid: Archivos, 1997. 361-75.

Benjamin, Walter. The Origin of German Tragic Drama. John Osborne, trad. Londres: Verso, 1998.

De Man, Paul. Blindness and Insight: Essays in the Rhetoric of Contemporary Criticism. 2a. ed. Minneapolis: U of Minnesota P, 1983.

Esposito, Roberto. Comunidad, inmunidad y biopolítica. Barcelona: Herder, 2009.

Fernández Retamar, Roberto. “Antipoesía y poesía conversacional en Hispanoamérica”. Para una teoría de la literatura hispanoamericana. Habana: Pueblo y Educación, 1984. 85-95.

Liano, Dante. "Algunas fuentes de El hombre que parecía un caballo y otros cuentos”. El hombre que parecía un caballo y otros cuentos. Rafael Arévalo, ed. Madrid: Archivos, 1997. 292-330.

"Nota filológica preliminar". El hombre que parecía un caballo y otros cuentos. Rafael Arévalo, ed. Madrid: Archivos, 1997. XXXI-XLII.

Martin, Gerald. "Rafael Arévalo Martínez y la lucha por la vida, o el hombre que parecía un ratoncillo”. El hombre que parecía un caballo y otros cuentos. Rafael Arévalo, ed. Madrid: Archivos, 1997. 261-91.

Nancy, Jean-Luc. La comunidad inoperante. Santiago: Arcis, 2000.

Paz, Octavio. Los hijos de limo: del romanticismo a la vanguardia. Santiago: Tajamar, 2008.

Said, Edward. El mundo, el texto, el crítico. Barcelona: Debate, 2004.

White, Hayden. The Content of the Form: Narrative Discourse and Historical Representation. Baltimore: Johns Hopkins UP, 1990.

\footnotetext{
$\begin{array}{lllll}\text { Revista Iberoamericana, Vol. LXXIX, Núm. 242, Enero-Marzo 2013, } 43-55 & \text { ISSN 2154-4794 (Electrónico) }\end{array}$
} 
